\title{
45
}

\section{Since Lawyers Work in Teams, We Must Focus on Team Ethics}

\author{
Justine Rogers ${ }^{\dagger}$
}

\section{Introduction}

James Hardie, AWB, McCabe, Foreman and the Catholic Church cases have revealed how ethical misconduct occurs within and by lawyers' teams. They have made clear that ethical decision-making and behaviour are beset by group dynamics and that individual morality corrodes without the right sort of consultation. This chapter presents team ethics as due for action, being a decisive but under-recognised part of lawyers' practice and morality.

Lawyers today need to know how to rely on and support each other in teams. People working in teams to pursue shared objectives is a basic fact of organisational functioning. ${ }^{2}$ Due to client demands, the complexity of issues and changing practice conditions, teamwork constitutes an increasing proportion of legal activity. ${ }^{3}$ This is particularly so in large law

\footnotetext{
1 Lecturer, University of New South Wales Law School.

2 Christopher P Neck and Charles C Manz, 'From Groupthink to Teamthink: Toward the Creation of Constructive Thought Patterns in Self-managing Work Teams' (1994) 47(8) Human Relations 929; Janet Weinstein and Linda H Morton, 'Collaboration and Teamwork' (2015) Faculty Scholarship Paper 163, 1.

3 H Gardner and M A Valentine, 'Collaboration Among Highly Autonomous Professionals: Costs, Benefits and Future Research Directions' in Shane Thyre and Edward J Lawler (eds), Advances in Group Processes (Emerald Group Publishing, 2015) 209; Weinstein and Morton, above n 2, 2.
} 
firms, and government and in-house departments. However, teams are also found in and cut across multiple legal entities and disciplines. ${ }^{4}$ Teams can be hierarchical or collaborative, ${ }^{5}$ and vary in their degrees of formality, stability and self-consciousness. ${ }^{6}$

Most importantly for this chapter, the team is a central mediator of ethics. All of us develop morally as members of social groups, including of our workplaces, which are now the central sites for lawyers' identities. More and more, lawyers recognise and resolve ethics issues within a team structure. Teams acquire strong or weak ethics cultures and voice climates. An 'ethics culture' consists of the organisation's formal structures and informal, shared and learned stories, attitudes and behaviour relevant to ethics. ${ }^{7}$ Culture to the organisation is what personality is to the individual: a hidden, yet unifying theme that provides meaning, direction and mobilisation. An 'ethics voice climate' gets at whether speaking up about ethics issues is encouraged, ${ }^{8}$ or whether, at the other end, there is a 'climate of silence. ' Within a single organisation, the teams' ethics cultures and climates can vary, and/or diverge from those of the organisation. These deviations can act as destabilising forces, ${ }^{10}$ though they also offer the possibility for new, positive ideas and routines to develop, for potential diffusion then throughout the organisation.

However, despite the expansion of team activity, legal practice is marked out, and typically perceived, as self-reliant and competitive. ${ }^{11}$ 'Lawyers often think about their own ethical behaviour as a matter of individual, independent judgment in the specific context of their own clients in their own situation'. ${ }^{12}$ The disciplinary architecture fortifies these beliefs. ${ }^{13}$ The conduct rules, for instance, attend to certain features of a lawyer's relationship with their colleagues, as people they may consult with on

4 Weinstein and Morton, above n 2, 2-3.

5 Gardner and Valentine, above n 3, 213-14.

6 Alex Steel, Anna Huggins and Julian Laurens, 'Valuable Learning, Unwelcome Assessment: What LLB and JD Students really think about Group Work' (2014) 36 Sydney Law Review 291.

7 Lei Huang and Ted A Paterson, 'Group Ethical Voice: Influence of Ethical Leadership and Impact on Ethical Performance’ (2014) 43 Journal of Management 1157.

8 Ibid. 3-4.

9 Elizabeth Wolfe Morrison and Frances J Milliken, 'Speaking Up, Remaining Silent: The Dynamics of Voice and Silence in Organizations' (2003) 40(6) Journal of Management Studies 1353.

10 Christine Parker et al, 'The Ethical Infrastructure of Legal Practice in Larger Law Firms: Values, Policy and Behaviour' (2008) 31 UNSW Law Journal 158, 173-74.

11 Weinstein and Morton, above n 2, 2.

12 Parker et al, above n 10, 166.

13 Ibid. 
ethical matters, but not as team-members working together, clarifying and defending ideas with one another, and whose behaviour affects that of others.

This chapter examines the scholarship and draws on the author's own (2014) study of UNSW law students' ethics capacities, to chart some of what we know about the influences of the team on ethics, both general and specific to law. The aim is to convey its sweeping significance to initiate change.

Part II outlines some of the negative potential impacts of the team on ethics. Part III examines the positive. The chapter uses Rest's model of ethical decision-making, developed between the 1980s and 1990s, to delineate these influences. Rest and his colleagues understood moral behaviour as involving at least four interlinked and necessary psychological components. The processes are:

1. Moralsensitivity or interpreting a situation as having ethical dimensions and imagining those affected and cause-effect chains of events.

2. Moral judgment or judging which action would be morally justified.

3. Moral motivation or giving priority to moral values over others, and taking personal responsibility for moral outcomes.

4. Moral character or having the courage to persist with moral action, overcoming fatigue, temptation and countervailing pressures. ${ }^{14}$

Rest's model recognised the affective and non-linear qualities inherent in moral behaviour. Nevertheless, his theory has been extensively criticised for its rationalist foundations, including by 'social intuitionist' scholars who have uncovered that moral judgment, one of Rest's components, is primarily made rapidly, emotionally and intuitively, and that any analysis is largely used to justify initial reactions. ${ }^{15}$ It is also regarded as too focused on the individual and not enough on their social and collective situations. Indeed, the primary content of this chapter comes from behavioural ethics

14 J R Rest, Moral Development: Advances in Research and Theory (Praeger, 1986); J R Rest, 'Background: Theory and Research' in J R Rest and D Narvaez (eds), Moral Development in the Professions: Psychology and Applied Ethics (LEA, 1994) (Postconventional Moral Thinking, 101-2; see page 10 for citations).

15 Jonathan Haidt, The Righteous Mind: Why Good People are Divided by Politics and Religion (Vintage, 2012); see, for example, list of sources in Robert A Prentice, 'Behavioral Ethics: Can it Help Lawyers (and Others) Be Their Best Selves' (2015) 29 Notre Dame Journal of Law, Ethics \& Public Policy 35, fn 124. 
research, a separate strand concerned with how people actually behave in moral contexts, and how the situation, specifically of being in a team, can nudge them towards or away from an ethical direction. ${ }^{16}$ Rest's framework is used here, notwithstanding, as a helpful way of breaking up the research, which was in fact its original function. Further, with its ultimate focus on improving outwardly observable behaviour by delineating at least some of the major prerequisites for ethical behaviour, it also suggests valuable lines of action for legal education and training, and organisational and regulatory change. Certain implications of this second, intuitive approach are addressed towards the chapter's end, which offer cautions for teambased ethics.

The conclusion is a set of recommendations for education, practice, regulation and scholarship. This proposal should be positioned within a wider reform movement that advocates for concepts of ethical conduct and accountability to be expanded to address their collective dimensions. ${ }^{17}$

\section{Negative Impacts of the Team on Ethics}

\section{A. Moral sensitivity}

- Fragmentation: teamwork separates people from the complete task, each other, the client, and others affected by their decisions, limiting the possibility for ethical awareness. ${ }^{18}$

- Self-confidence bias: teams assume their inherent morality and may, then, perceive moral questioning as unnecessary or even threatening. ${ }^{19}$

- Moral exclusion: teamwork can encourage beliefs that only members, or powerful members within it, are entitled to moral considerations. ${ }^{20}$

16 Max H Bazerman and Francesco Gino, 'Behavioral Ethics: Towards a Deeper Understanding of Moral Judgment and Dishonesty', Annual Review of Law \& Social Science (forthcoming) 9.

17 Kimberly Kirkland, 'Ethics in Large Law Firms: The Principle of Pragmatism' (2005) 35 University of Memphis Law Review 631; Parker et al, above n 10; Milton C Regan Jr, 'Nested Ethics: A Tale of Two Cultures' (2013) 42 Hofstra Law Review 143.

18 Parker et al, above n 10, 163-65.

19 Irving L Janis, Groupthink: Psychological Studies of Policy Decisions and Fiascoes (Houghton Mifflin, $\left.2^{\text {nd }} e d n, 1982\right) 256-57$.

20 Parker et al, above n 10, 165. 


\section{B. Moral judgment}

- Groupthink: cohesive groups tend to strive for consensus and make assumptions about unanimity. Their members self-censor, ignore alternatives, and dehumanise outsiders, ${ }^{21}$ or at least polarise their views to accord with those of the leader or majority. ${ }^{22}$

- Conformity bias: the inclination to coordinate or comply is stronger if members have identified with the group or if they risk exclusion or shame. $^{23}$

- In-group bias: outside voices tend to be restrained since they represent interruptions to valued relationships within the team. ${ }^{24}$ As a pertinent, though less obvious example, the legal academic-teacher is, to some extent, an outside voice in their students' analyses of legal ethical issues. The students have already begun to forge relationships, real and imagined, with the legal profession. A student in my research told me: 'I want to hear from law firms and lawyers that being ethical is in their best interests, not just from academics'.

\section{Moral motivation}

- Diffusion of obligation: team members can believe that responsibility for ethical issues lies with someone else. ${ }^{25}$

- Myth of invisibility: a team can give individuals a sense of protection from outside scrutiny. ${ }^{26}$

- In general, group work encourages learned passivity. ${ }^{27}$

21 Janis, above n 19.

22 Cass R Sunstein and Reid Hastie, Wiser: Getting beyond Groupthink to Make Groups Smarter (Harvard Business Press, 2015).

23 Janis, above n 19, 5-8; Patricia H Werhane et al, Obstacles to Ethical Decision-making: Mental Models, Milgram and the Problem of Obedience (Cambridge University Press, 2013) 102-3.

24 Ibid. 106.

25 Jennifer K Robbennolt and Jean R Sternlight, 'Behavioral Legal Ethics' 45(3) (2013) Arizona State Law Journal 1107, 1149.

26 Werhane et al, above n 23, 116.

27 Ibid. 119. 


\section{Moral action}

An individual in a group may decide not to speak up or otherwise persist in unethical behaviour if the costs outweigh the benefits. ${ }^{28}$ These assessments can be inaccurate both ways; that moral action would or would not be worthwhile..$^{29}$ There are three risk factors:

\section{Safety}

Raising an ethics issue can upset relationships within the group, ${ }^{30}$ and risks, or is seen to risk, ${ }^{31}$ labelling, exclusion and retaliation. ${ }^{32}$ To make this assessment, team members use social information about culture and climate, primarily the leader's informal conduct, including any undermining behaviours, ${ }^{33}$ as well as the leader's routine attitudes towards uncertainty and mistakes. ${ }^{34} \mathrm{~A}$ climate of silence is related to a punitive culture, or a workplace in which it is not safe for employees to raise and learn from their mistakes.

\section{Likely impact}

Individuals assess their likely ability to initiate change in relation to their level of autonomy in their job. ${ }^{35}$ They also evaluate whether past wrongdoers were disciplined ${ }^{36}$ and systemic problems corrected, ${ }^{37}$ or whether raising the issue was, or seemed, futile. ${ }^{38} \mathrm{~A}$ student reported: 'I would need evidence that something was done about complaints to bother reporting anything'.

28 Jeffrey A LePine and Linn Van Dyne, 'Predicting Voice Behavior in Work Groups' (1998) 83(6) Journal of Applied Psychology 853.

29 Ethan R Burris, 'The Risks and Rewards of Speaking Up: Managerial Responses to Employee Voice' (2012) 55(4) Academy of Management Journal 851.

30 Shahidul Hassan, 'The Importance of Ethical Leadership and Personal Control in Promoting Improvement-Centered Voice among Government Employees' (2015) 25(3) Journal of Public Administration Research and Theory 697.

31 Gardner and Valentine, above n 3.

32 James R Detert and Ethan R Burris, 'Leadership Behavior and Employee Voice: Is the Door really Open?' (2007) 50(4) Academy of Management Journal 869.

33 M Lance Frazier and Wm Matthew Bowler, 'Voice Climate, Supervisor Undermining, and Work Outcomes: A Group-Level Examination' (2015) 41(3) Journal of Management 841.

34 Detert and Burris, above $\mathrm{n} 32$.

35 Hassan, above n 30, 703; Robbennolt and Sternlight, above n 25, 1180.

36 Linda K Trevińo, Gary R Weaver and Scott J Reynolds, 'Behavioral Ethics in Organizations:

A Review' (2006) 32(6) Journal of Management 951.

37 Robbennolt and Sternlight, above n 25, 1179.

38 Prentice, above n 15, 40; Huang and Paterson, above n 7, 7-8. 


\section{Harm to other interests}

The benefits of collaboration appear to accrue at the collective. ${ }^{39}$ This appears wasteful within a 'stars culture' in which the individual's expertise and client relationships generate status. ${ }^{40}$ Further, the team itself can act as the centre of patronage networks needed for advancement as well as a mechanism of evaluation. Research into government professionals shows a negative relationship between performance monitoring and 'improvement-centred employee voice', or the propensity to make suggestions to improve the organisation, including its ethical culture. ${ }^{41}$ One student said: 'To be ethical, I'd need to see support for the person voicing the concern, proof that you won't be condemned or bullied or overlooked for promotion'.

The strain of group dynamics has an upsetting, diminishing influence on each of these components. Teamwork can deplete time and cognitive resources as energy is diverted to impression management, and the logistics of organising and integrating expertise. ${ }^{42}$ Lawyers tend to be more self-protective, less interpersonally sensitive and less steady in the face of pressure than the general population. ${ }^{43}$ Teamwork can create extra feelings of exposure and incompetence. ${ }^{44}$ Shame tends to lead to turning inward and away from others, ${ }^{45}$ and fear of exclusion can result in contempt towards the team. ${ }^{46}$ Though not a typical response, one student reported that teamwork in my course was 'bad for wellbeing and reminded me of high school'. Nonetheless, there is potential for team-based ethics to be highly beneficial and productive.

39 Gardner and Valentine, above n 3, 215.

40 Gardner and Valentine, above n 3.

41 Hassan, above n 30, 714.

42 Gardner and Valentine, above n 3, 215.

43 L Richard and L Rohrer, 'A Breed Apart?' (2011) The American Lawyer 43.

44 Elisabeth Dunne and Mike Rawlins, 'Bridging the Gap between Industry and Higher Education: Training Academics to Promote Student Teamwork' (2000) 37 Innovations in Education and Teaching International 361; Steel, Huggins and Laurens, above n 6, 318-19.

45 Treviño, Weaver and Reynolds, above n 36.

46 Madan M Pillutla and Stefan Thau, 'Actual and Potential Exclusion as Determinants of Individuals' Unethical Behaviour in Groups' in David DeCremer (ed), Psychological Perspectives on Ethical Behaviour and Decision-Making (IAP, 2009) 107. 


\section{Positive Impacts of the Team on Ethics}

\section{A. and B. Moral sensitivity and moral judgment}

A team has the potential to enhance ethical sensitivity and judgment by increasing the chance that someone will detect the ethics issue in the first place, and then by offering the opportunity to examine a wider survey of beliefs about the problem and the objectives for addressing it. Further, a team presents the possibility for an analytical process in which stereotyping about stakeholders is reduced and the range of harms likely to be considered is extended. ${ }^{47}$

\section{Moral motivation}

A team identity grounded in ethics is a powerful, intrinsic motivator if it is meaningful for members ${ }^{48}$ within their specific context. A team with a salient ethical identity is more likely to foster a collective confidence in which ethical issues are regarded as opportunities not threats. ${ }^{49}$ Indeed, members come to regard unethical conduct as a form of harm to their team, which must be managed and prevented. ${ }^{50}$

\section{Moral action}

Ethics leadership is arguably the most determinative of whether or not a member or members of a team are likely to seek to resolve an ethics issue, at all or at least by seeking advice from within the team. An ethical leader is an ethical role model who treats people fairly and actively gives the team the context to prepare for and engage in critical, ethical thinking, including by having a discussion without the leader's presence if that is likely to improve ethical dialogue. ${ }^{51}$ Ethical leaders recognise their colleagues' uniqueness, ask extra questions to encourage deeper conversation, follow up on ethical decisions, ${ }^{52}$ and adopt a change-

47 Werhane et al, above n 23, 104.

48 Robbennolt and Sternlight, above n 25, 1181.

49 Marlene E Turner et al, 'Threat, Cohesion, and Group Effectiveness: Testing a Social Identity Maintenance Perspective on Groupthink' (1992) 63(5) Journal of Personality and Social Psychology 781.

50 Treviño, Weaver and Reynolds, above n 36, 969; Robbennholt and Sternlight, above n 25, 1177.

51 Hassan, above n 30, 701-2.

52 LePine and Van Dyne, above n 28. 
oriented style. ${ }^{53}$ The types of conversations they guide advance ethics-asdeliberation and ethics-as-possibility. ${ }^{54}$ The phenomenon becomes, then, 'teamthink', not groupthink. ${ }^{55}$

The relevant leader here is someone with whom the team regularly interacts. In more collaborative, ad hoc groups, with potentially shifting memberships, these issues are more challenging since much of the value of teams of which we know rests on time and trust.

\section{A Couple of Cautions}

\section{A. The deliberative ethics problem}

A rational, reflective approach would seem to be vital in reducing the harmful psychological drives induced by the team and the non-conscious emotions that can bedevil our responses to ethics issues when left on our own. However, putting aside here an important debate about the ultimate power of emotion and intuition over reason, in certain circumstances, automatic responses are more ethically appropriate. ${ }^{56}$ Deliberation can disrupt these responses by strengthening attachments to rule-guided criteria and/or by increasing the chances of non-moral factors being considered. ${ }^{57}$

\section{B. The team ethics problem}

The necessity for outsider input to the team to help reduce the risks of ethical parochialism and fading has already been implied in the discussion so far. In addition to this external contribution, individual team members must retain the identity space ${ }^{58}$ for their own, independent reflection. Where needed, lawyers must be able to make disclosures about or otherwise exercise dissent against the team and the client, separate from team processes.

53 Detert and Burris, above $\mathrm{n} 32$.

54 Neck and Manz, above n 2; Mark G Edwards and Nin Kirkham, 'Situating "Giving Voice to Values": A Metatheoretical Evaluation of a New Approach to Business Ethics' (2014) 121(3) Journal of Business Ethics 477.

55 Neck and Manz, above n 2.

56 Chen-Bo Zhong, 'The Ethical Dangers of Deliberative Decision Making' (2011) 56.1

Administrative Science Quarterly 1.

57 Ibid.

58 G R Weaver, 'Virtue in Organizations: Moral Identity as a Foundation for Moral Agency' (2006)

27(3) Organization Studies 341. 


\section{Implications}

\section{A. Legal education and training}

National university regulations and the 'Threshold Learning Outcomes' for law now stipulate that law students acquire and be able to demonstrate skills in collaboration. ${ }^{59}$ Meanwhile, a growing body of research is establishing the positive links between teamwork, and achievement, critical thinking, problem-solving ability, creativity and wellbeing. ${ }^{60}$ Nonetheless, teamwork remains a fringe part of the law degree, and there is, unfortunately, scant pedagogical material to use to teach teamwork and its relationship to lawyers' ethics.

Until this material is developed, at the very least, educators need to make law students and lawyers aware of the ways in which teams impact ethical decision-making and behaviour. More helpful also would be to inculcate in students skills to deliver and receive ethics information within a team. ${ }^{61}$ In light of the cautions above, the emphases here should be on dialogue, possibility and action. ${ }^{62}$

\section{B. Legal practice}

Managers and other professional leaders should support the educational suggestions above. Moreover, they need to recognise, develop and reward ethical lawyers at each level and across each team-type. Research shows that those in a team with higher moral reasoning are not more likely than others to emerge as leaders. Firms need to consider actively identifying these individuals for leadership programs. ${ }^{63}$

They also need to contemplate how ethical behaviour is to be reinforced within and across teams. Valuable starting questions might be: 'What sorts of conversations do we need to engage in to help bring our core

59 Australian Learning \& Teaching Council, Resources to Assist Discipline Communities to Define Threshold Learning Outcomes (TLOS): An Outcome of the ALTC's Learning and Teaching Academic Standards (LTAS) Project (Australian Government Department of Education, Employment and Workplace Relations, Canberra, 2011) 5. See Steel, Huggins and Laurens, above n 6, 297-98.

60 Ibid. 295.

61 An excellent base is Mary Gentile's Giving Voice to Values program, currently used at ANU College of Law and UNSW Law.

62 Edwards and Kirkham, above n 54.

63 Treviño, Weaver and Reynolds, above n 36, 957. 
ethical concerns [and obligations] and those of others into the open?'64 Are these conversations likely to happen in light of the rest of our firm culture and climate? These may need to be considered for intra-firm, inter-disciplinary, cross-jurisdictional and global teams as well. ${ }^{65}$

\section{Professional regulation}

Team-based ethics should be a part of the profession's Continuing Professional Development (and assessment?). More contestable is the tacit case for team-based regulation and discipline.

\section{Legal scholarship}

Writers have called for more research on the team as an ethical decisionmaking unit and on team-level ethical phenomena. ${ }^{66}$ Some lines of inquiry that would be fruitful are:

- Types of ethical cultures and climates within hierarchical and collaborative teams, and within and across legal practices.

- What kinds of ethical discussion currently take place and among whom? ${ }^{\text {67 }}$

- What types of ethics issues are addressed and which are off-limits?68 Are discussions in terms of rules or do they include values behind rules? ${ }^{69}$ Whose behaviour or objectives are (allowed to be) questioned?

- When might unethical conduct of a team require team discipline?

- Is the client part of the team? Is it possible to say, in certain situations, that the client is the leader of the team? What does this mean for lawyers' ethics?

- Finally, does teamwork in law firms improve, or have potential to improve, ethical outcomes?

64 M G Edwards et al, 'Voicing Possibilities: A Performative Approach to the Theory and Practice of Ethics in a Globalised World' in D E Palmer (ed), Handbook of Research on Business Ethics and Corporate Responsibilities (InfoSci-Books, 2015) 249.

65 Ibid.

66 Trevińo, Weaver and Reynolds, above n 36, 968.

67 Burris, above n 29, 870.

68 Huang and Paterson, above n 7, 2.

69 Parker et al, above $\mathrm{n} 10$. 
This text is taken from New Directions for Law in Australia: Essays in Contemporary Law Reform, edited by Ron Levy, Molly O’Brien, Simon Rice, Pauline Ridge and Margaret Thornton, published 2017 by ANU Press, The Australian National University, Canberra, Australia. 